\title{
A human microRNA precursor binding to folic acid discovered by small RNA transcriptomic SELEX
}

\author{
NAOHIRO TERASAKA, ${ }^{1,3}$ KAZUKI FUTAI, ${ }^{1,4}$ TAKAYUKI KATOH, ${ }^{1}$ and HIROAKI SUGA ${ }^{1,2}$ \\ ${ }^{1}$ Department of Chemistry, Graduate School of Science, The University of Tokyo, 7-3-1 Hongo, Bunkyo-ku, Tokyo 113-0033, Japan \\ ${ }^{2}$ JST, CREST, The University of Tokyo, Tokyo 113-0033, Japan
}

\begin{abstract}
RNA aptamers are structured motifs that bind to specific molecules. A growing number of RNAs bearing aptamer elements, whose functions are modulated by direct binding of metabolites, have been found in living cells. Recent studies have suggested that more small RNAs binding to metabolites likely exist and may be involved in diverse cellular processes. However, conventional methods are not necessarily suitable for the discovery of such RNA aptamer elements in small RNAs with lengths ranging from $\mathbf{5 0}$ to 200 nucleotides, due to the far more abundant tRNAs in this size range. Here, we describe a new in vitro selection method to uncover naturally occurring small RNAs capable of binding to a ligand of interest, referred to as small RNA transcriptomic SELEX (smaRtSELEX). By means of this method, we identified a motif in human precursor microRNA 125a (hsa-pre-miR-125a) that interacts with folic acid. Mutation studies revealed that the terminal loop region of hsa-pre-miR-125a is important for this binding interaction. This method has potential for the discovery of new RNA aptamer elements or catalytic motifs in biological small RNA fractions.
\end{abstract}

Keywords: SELEX; small RNA; microRNA; ribozyme; folic acid

\section{INTRODUCTION}

RNA aptamers are structured motifs exhibiting high specificity and affinity to their target molecules. Various RNA aptamers have been obtained by in vitro selection, termed SELEX (systematic evolution of ligands with exponential enrichment) (Ellington and Szostak 1990; Tuerk and Gold 1990; Stoltenburg et al. 2007). SELEX was initially developed to isolate nucleic acid aptamers from random sequences, but several modified SELEX methods have been developed to identify RNA aptamer elements in biological transcripts (Stoltenburg et al. 2007). For example, genomic SELEX, where the RNA library is derived from the genomic DNA, enables the identification of novel RNA aptamer elements coded in genomes (Singer et al. 1997). However, post-transcriptionally processed RNA sequences (e.g., resulting from splicing, nontemplated addition of nucleotides [KoppersLalic et al. 2014] and circular permutation [Pan and Uhlenbeck 1993]) cannot be discovered by genomic SELEX because the library is derived from the genome. Moreover, genomic SELEX may select biologically irrelevant sequences that are not transcribed in vivo. To overcome these problems, RNA

\footnotetext{
${ }^{3}$ Present address: Laboratory of Organic Chemistry, ETH Zurich, 8093 Zurich, Switzerland

${ }^{4}$ Present address: Medical and Biological Laboratories Co., Ltd., 1063103 Terasawaoka, Ina, Nagano 396-0002, Japan

Corresponding author: hsuga@chem.s.u-tokyo.ac.jp

Article published online ahead of print. Article and publication date are at http://www.rnajournal.org/cgi/doi/10.1261/rna.057737.116.
}

libraries from natural transcripts have been used for SELEX, which has been referred to as cDNA-SELEX (Dobbelstein and Shenk 1995; Chen et al. 2003) or transcriptomic SELEX (Fujimoto et al. 2012). These methods have been widely used to analyze RNA-protein interaction networks (Zimmermann et al. 2010). In addition to endogenous RNA aptamers that bind to proteins, many metabolite-binding RNA aptamer elements have also been discovered in natural transcripts (Serganov and Nudler 2013).

The best characterized class of naturally occurring RNA aptamers that bind to metabolites are riboswitches. These are regions of mRNAs containing RNA aptamer domains that bind to metabolites linked to expression platforms that enable regulation of associated coding sequences (Serganov and Nudler 2013). Riboswitches have been identified by computational analysis based on phylogenetic conservation of RNA aptamer sequences and structural stability (Weinberg et al. 2007, 2010; Serganov and Nudler 2013). Although more than 20 classes of riboswitches sensing purines, coenzymes, amino acids, metals, and anions have been discovered in bacteria (Serganov and Nudler 2013), only TPP (thiamine pyrophosphate)-dependent riboswitches exist in algae, fungi, and plants and none have been identified in other eukaryotes.

\footnotetext{
C 2016 Terasaka et al. This article is distributed exclusively by the RNA Society for the first 12 months after the full-issue publication date (see http://rnajournal.cshlp.org/site/misc/terms.xhtml). After 12 months, it is available under a Creative Commons License (Attribution-NonCommercial 4.0 International), as described at http://creativecommons.org/licenses/bync/4.0/.
} 
In eukaryote transcripts, some metabolite-binding RNA aptamer sequences, which differ from riboswitches, have been discovered recently by the combination of computational prediction and genomic SELEX. Adenosine-binding RNA aptamers were discovered in mRNAs of several vertebrates including humans (Vu et al. 2012), and it was reported that G-motifs with G-quadruplexes and CA-rich motifs in eukaryotic genes possess GTP-binding activity (Curtis and Liu 2013, 2014). Although the detailed biological roles of these RNAs remain to be elucidated, these discoveries indicate that metabolite-binding RNA aptamer sequences exist in eukaryotes and may post-transcriptionally regulate the biological roles of RNAs in a manner similar to riboswitches.

In contrast to bacteria, eukaryotes have various small functional, but noncoding, RNAs shorter than $200 \mathrm{nt}$, such as miRNA, small nucleolar RNA (snoRNA), and small nuclear RNA (snRNA), which are known to play important roles in various cellular processes (Huttenhofer et al. 2002). In addition to RNA aptamer sequences in eukaryotic mRNAs, it has recently been reported that the expression of human microRNA-33a (hsa-miR-33a) and hsa-miR-122 is modulated by direct binding of specific polyphenols, such as epigallocatechin gallate and resveratrol (Baselga-Escudero et al. 2014). This suggests that the existence of RNA aptamer elements is not limited in mRNAs and is widespread in various transcripts, including small noncoding RNAs in eukaryotes. Binding of metabolites to small RNAs introduces the potential for novel post-transcriptional regulatory mechanisms, and the discovery of additional RNA aptamer elements in small RNAs is therefore an important area for further study. However, in the case of conventional SELEX methods, natural small RNAs cannot be directly used for the construction of a library, because the far more abundant 5S/5.8S rRNAs and tRNAs in small RNA fractions greatly complicate isolation and identification of the desired RNA molecule. Therefore, it is necessary to develop a new method that enables the identification of RNA aptamer elements from small RNA fractions.

Here, we report a method for the selection of small RNA aptamers from a pool derived from naturally occurring small RNAs, referred to as small RNA transcriptomic SELEX (smaRt-SELEX) (Fig. 1A). A key step in smaRt-SELEX is the depletion of the abundant populations of rRNAs and tRNAs from the small RNA fraction. Here we have adopted a commercial method using oligonucleo- tide probes that are complementary to rRNAs for rRNA removal, and the tRid method recently developed in our laboratory that enables us to remove total tRNA. The latter technique involves the use of a modified flexizyme, referred to as dial-Fx, which is utilized to deplete the RNA sample of total tRNA through charging with $N$-biotinylated phenylalanine (Biotin-Phe) (Futai et al. 2016). In this work, we have demonstrated smaRt-SELEX against folic acid (Fig. 1B), one of the water-soluble vitamins. This experiment has led to the discovery of a human precursor microRNA motif, known as hsa-pre-miR-125a, in which the terminal loop region interacts with folic acid.

\section{RESULTS}

\section{Construction of the rRNA/tRNA-depleted human small RNA library}

To discover small RNAs that interact with a target molecule, we constructed an rRNA/tRNA-depleted human small RNA library ranging from 10 nucleotides (nt) to $200 \mathrm{nt}$ (Fig. 1A). Because rRNAs and tRNAs are much more abundant in RNA fractions smaller than about $200 \mathrm{nt}$, these RNAs should be depleted as much as possible in order to selectively enrich a

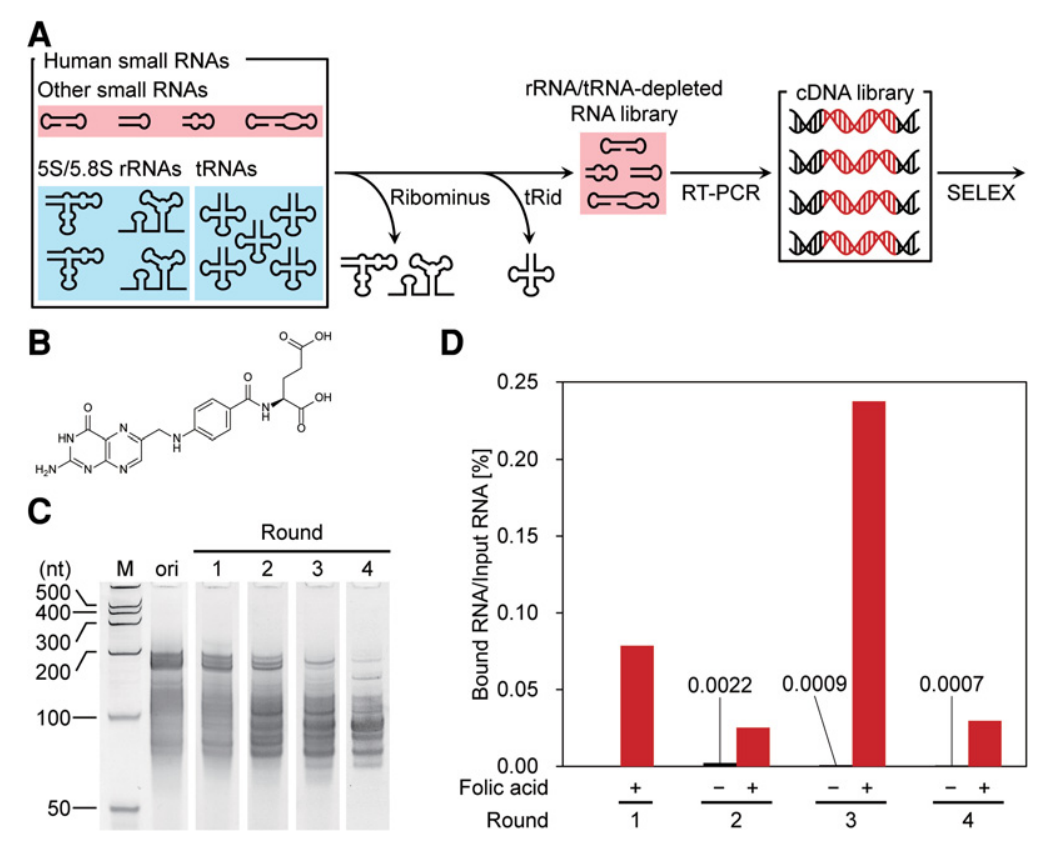

FIGURE 1. Isolation of folic acid binding small RNAs using smaRt-SELEX. (A) Schematic illustration of smaRt-SELEX. From the small RNA fraction, the $5 \mathrm{~S}$ and $5.8 \mathrm{~S}$ rRNAs were removed using probes complementary to these rRNAs (RiboMinus, Life Technologies), and then tRNAs were depleted using the tRid method. The rRNA/tRNA-depleted small RNA library was converted to cDNA by RT-PCR and SELEX was performed. $(B)$ Chemical structure of folic acid. $(C)$ Polyacrylamide gel analysis of the RNA library from each round of smaRt-SELEX. M indicates the RNA marker; "ori” indicates the RNA library before smaRt-SELEX. $(D)$ Bead-binding activity of RNAs from each round of the smaRt-SELEX. Proportional binding was determined by normalizing bound quantities to input quantities of RNA. Black bars indicate binding of RNA to hydroxyl-beads that were not conjugated to folic acid, and red bars indicate binding of RNA to folic acidimmobilized beads. Hydroxyl-beads were not used in the first round. 
pool of small RNAs. Fractions of such small RNAs were extracted from seven human cell lines (BeWo, HuH-7, VMRC-RCW, NEC14, HuO-3N1, RAJI, and MCF7) and combined into a pool. Then, from this pool of small RNAs, rRNAs were depleted using commercial oligonucleotide probes complementary to rRNAs (Supplemental Fig. S1A, RiboMinus, Life technologies). To remove total tRNAs, we used tRid methodology (Futai et al. 2016), recently developed in our laboratory using a modified flexizyme. In this method, we used a $3^{\prime}$-oxidized dialdehyde-flexizyme (dial-Fx) to aminoacylate the total tRNA fraction in the extract with $N$-biotinylated phenylalanine (Biotin-Phe) essentially irrespective of sequence, and the biotin-tagged tRNAs were then effectively removed from other small RNAs by the use of streptavidinimmobilized magnetic beads (Supplemental Figs. S1B-D).

The rRNA/tRNA-depleted fraction of human small RNAs was ligated to $5^{\prime}$ - and $3^{\prime}$-adaptor oligonucleotides, yielding a library of small RNAs. This library was then amplified by RTPCR and cloned for sequencing in order to confirm that an appropriate population had been obtained. In comparison with the crude fraction of small RNAs, the population of non-rRNA/tRNA small RNAs was suitably enriched, with only $24 \%$ and $9 \%$ of tRNAs (including non-CCA tRNA fragments and pre-tRNAs) and rRNAs, respectively, remaining in the final fraction (the total number of sequences was 89, Supplemental Fig. S2; Supplemental Table S1). This small RNA-enriched library was deemed to be applicable to smaRtSELEX against a target molecule.

\section{smaRt-SELEX against folic acid}

Folic acid is the synthetic form of the vitamin folate (MelseBoonstra et al. 2004). It is essential for nucleotide synthesis, and its deficiency is linked to developmental anomalies (Mulinare et al. 1988) and an increased risk for a number of cancers (Jiang et al. 2003). Moreover, a riboswitch motif that senses folate has been described previously (Ames et al. 2010). To demonstrate the smaRt-SELEX, we chose folic acid as a target to select functional small RNAs from the aforementioned small RNA library. The library was mixed with folic acid immobilized on magnetic beads and bound
RNAs were eluted with free folic acid, amplified by RTPCR, and transcribed to generate RNA pools for the next round of selection. Four rounds of the smaRt-SELEX were conducted while the selection conditions were gradually made more stringent (see Materials and Methods). PAGE analysis of the RNA library indicated that the fractions of small RNAs bound to the folic acid beads were enriched over the background and several discrete bands appeared (Fig. 1C,D). The RNA pool at the fourth round was then cloned and sequenced (Table 1; Supplemental Table S2).

Among the 40 clones analyzed by the sequence alignment, we have identified three families of RNAs observed multiple times (Table 1). Two of the three RNAs were not fully matched to human transcripts, referred to as FA1 and FA2. FA1 is an antisense sequence of a part of mitochondrial mRNA of ND1 (NADH dehydrogenase 1) bearing an additional poly-A/C sequence at the $3^{\prime}$ end, which is not coded in the genome. FA2 is a $5^{\prime}$ fragment of $\mathrm{tRNA}^{\mathrm{Gly}}{ }_{\mathrm{GCC}}$ lacking 3' nucleotides, which was discovered as a small RNA (tRF3006) (Lee et al. 2009). On the other hand, one of the three was fully matched to human precursor miRNA-125a (hsa-pre-miR-125a). We prepared these three RNAs with the adaptors (FA1 + adp, FA2 + adp, has-pre-miR125a + adp) by in vitro transcription and compared them with the RNA library of the fourth round in denaturing PAGE (Supplemental Fig. S3). Because the sizes of three RNAs are 87, 88, and $96 \mathrm{nt}$, the observed intense band in the RNA library should correspond to these lengths. In further investigations, we decided to focus on these three small RNAs.

\section{Binding affinity of obtained RNAs to folic acid}

Since the $3^{\prime}$ - and 5'-adpators were ligated with naturally transcribed RNAs for RT-PCR during the smaRt-SELEX, it was necessary to validate that the binding ability of the selected clones did not rely on the presence of the adaptors. The secondary structures of FA1 and FA2 predicted by mfold (Zuker 2003 ) indicated that the placement of these adaptors relative to these motifs (referred to as FA1 + adp and FA2 + adp in Supplemental Fig. S4) resulted in a dramatic change in the respective secondary structures compared with the parental

TABLE 1. RNAs obtained after the smaRt-SELEX against folic acid and $K_{\mathrm{D}}$ values of each RNA with or without adaptor sequences

\begin{tabular}{|c|c|c|c|c|c|c|}
\hline \multirow[b]{2}{*}{ RNA } & \multirow[b]{2}{*}{ Sequence $\left(5^{\prime}\right.$ to $\left.3^{\prime}\right)$} & \multirow[b]{2}{*}{ Frequency } & \multicolumn{2}{|c|}{ With adaptors } & \multicolumn{2}{|c|}{ Without adaptors } \\
\hline & & & $K_{\mathrm{D}}(\mu \mathrm{M})$ & $R^{2}$ & $K_{\mathrm{D}}(\mu \mathrm{M})$ & $R^{2}$ \\
\hline FA1 & $\begin{array}{l}\text { UUUUAUGGCGUCAGCGAAGGGUUGUAGUAG } \\
\text { CCCGUAAAAACCAAAAAAACC }\end{array}$ & $20 / 40$ & 3.8 & 0.98 & ND & ND \\
\hline FA2 & $\begin{array}{l}\text { GCAUUGGUGGUUCAGUGGUAGAAUUCUCGCCU } \\
\text { GCCACGCGGGAGGCCCGGGU }\end{array}$ & $7 / 40$ & ND & ND & ND & ND \\
\hline hsa-pre-miR-125a & $\begin{array}{l}\text { UCCCUGAGACCCUUUAACCUGUGAGGACAUCCA } \\
\text { GGGUCACAGGUGAGGUUCUUGGGAGCC }\end{array}$ & $2 / 40$ & 1.9 & 0.97 & 2.8 & 0.98 \\
\hline
\end{tabular}

(ND) Not detectable. $K_{\mathrm{D}}$ values were derived by fitting the increase in BLI signal as a function of RNA concentration using the Octet data analysis software. $R^{2}$ values were derived from curve fitting. 
motifs. On the other hand, the structure of hsa-pre-miR$125 \mathrm{a}$ remained the same even when the adaptors were included in the folding model (referred to as hsa-pre-miR-125a + adp in Supplemental Fig. S4). These predictions suggested that the $3^{\prime}$ - and $5^{\prime}$-adaptors possibly altered the original motif of FA1 and FA2 but unlikely did the same to the hsa-premiR-125a motif.

The dissociation constant $\left(K_{\mathrm{D}}\right)$ values of RNAs to folic acid were measured using biolayer interferometry (BLI) analysis. To immobilize folic acid onto the biosensors, ethylenediamine was immobilized onto AR2G (amine reactive second-generation) biosensors whose surface bears a carboxyl group. The carboxyl groups of folic acid were then conjugated to this sensor via an amide bond. The $K_{\mathrm{D}}$ values were measured by fitting the increasing values of the BLI signal as a function of RNA concentrations (Table 1). As predicted from the mfold analysis, FAl with the adaptors was able to bind to folic acid with $K_{\mathrm{D}}$ of $3.8 \mu \mathrm{M}$, whereas the motif itself without the adapters did not exhibit binding activity. This result indicates that the adaptors play a role in forming an active structure with FA1 for binding to folic acid, likely predicted by the mfold analysis (Supplemental Fig. S4). On the other hand, we were unable to detect folic acid binding of FA2 regardless of the presence of the adaptors. Since the support materials for immobilization of folic acid between this assay and selection are different, the supporting material on the beads used for selection might be involved in the binding of FA2 + adap to folic acid.

In contrast to FA1 and FA2, the hsa-pre-miR-125a was able to bind to the folic acid regardless of the presence of the adaptors, giving comparable $K_{\mathrm{D}}$ values of $2.8 \mu \mathrm{M}$ and $1.9 \mu \mathrm{M}$ for hsa-pre-miR-125a and hsa-pre-miR-125a + adp, respectively. This result indicates that the motif of hsa-premiR-125a itself has an ability to bind to folic acid. We thus hypothesized that it has a binding core capable of directly interacting with folic acid. The concentrations of folic acid in human cytoplasm were reported as $0.735 \mu \mathrm{M}(0-30 \mathrm{~d}$ old $)$, $0.453 \mu \mathrm{M}$ (>18 yr old) in the human metabolome database (Wishart et al. 2013), which are about fivefold lower concentration than the $K_{\mathrm{D}}$ value we measured. However, the cell environment is molecularly crowded more than the typical in vitro solution experiments, and therefore the molecular crowding effects could influence the binding of folic acid to hsa-pre-miR-125a. In fact, when adding 20\% PEG200 to binding buffer to mimic the crowded conditions in cells, the $K_{\mathrm{D}}$ value decreased from 2.6 to $0.47 \mu \mathrm{M}$ (Table 2), which is a relevant level of the concentration in cytoplasm.

\section{The terminal loop region in hsa-pre-miR125a is essential for binding}

To define the binding core existing in the hsa-pre-miR-125a motif, it was necessary to facilitate the preparation of various mutants. To achieve this, we first introduced U1G/G58C mutations to the hsa-pre-miR-125a. This mutation did not alter
TABLE 2. $K_{\mathrm{D}}$ values of hsa-pre-miR-125a mutants

\begin{tabular}{|c|c|c|c|c|}
\hline RNA & Mutation & $K_{\mathrm{D}}(\mu \mathrm{M})$ & Relative value & $R^{2}$ \\
\hline hsa-pre-miR-21 & U1G & ND & - & ND \\
\hline hsa-pre-miR- & No (WT) & 2.8 & 1 & 0.98 \\
\hline \multirow[t]{2}{*}{$125 a$} & U1G/G58C & 2.6 & 0.93 & 0.99 \\
\hline & U1G/G58C* & 0.47 & 0.17 & 0.99 \\
\hline hsa-pre- & StemM1 & 4.6 & 1.6 & 0.98 \\
\hline miR-125a & StemM2 & 6.2 & 2.2 & 0.99 \\
\hline \multirow{27}{*}{ U1G/G58C } & U22G/A39C & 2.1 & 0.75 & 0.98 \\
\hline & G23C/C38G & 3.2 & 1.1 & 1.00 \\
\hline & A24U/U37A & 3.2 & 1.1 & 0.99 \\
\hline & LoopM1 & ND & - & ND \\
\hline & LoopM2 & 4.2 & 1.5 & 0.88 \\
\hline & G25A/C32U & 62 & 22 & 0.96 \\
\hline & G26C/C31G & 48 & 17 & 0.95 \\
\hline & $\mathrm{C} 32 \mathrm{U}$ & 32 & 11 & 0.98 \\
\hline & A33U & 3.0 & 1.1 & 0.96 \\
\hline & G34A & 38 & 14 & 0.94 \\
\hline & G35A & ND & - & ND \\
\hline & G36A & 35 & 13 & 0.99 \\
\hline & $\Delta \mathrm{A} 33$ & 11 & 3.9 & 1.00 \\
\hline & A33a & 48 & 17 & 0.93 \\
\hline & $\Delta \mathrm{A} 24$ & ND & - & ND \\
\hline & $\Delta \cup 37$ & ND & - & ND \\
\hline & U37A & 2.1 & 0.75 & 0.95 \\
\hline & U37A/C38G & ND & - & ND \\
\hline & G25A & 73 & 26 & 0.99 \\
\hline & G26C & 62 & 22 & 0.99 \\
\hline & C31G & 6.0 & 2.1 & 0.99 \\
\hline & $\mathrm{C} 32 \mathrm{G}$ & 11 & 3.9 & 0.99 \\
\hline & $\Delta \mathrm{C} 28$ & 1.8 & 0.64 & 0.96 \\
\hline & $\Delta \mathrm{C} 28 / \mathrm{A} 29$ & 1.4 & 0.5 & 0.94 \\
\hline & $\Delta \mathrm{C} 28-\mathrm{U} 30$ & 1.2 & 0.43 & 0.93 \\
\hline & $\Delta \mathrm{A} 27-\mathrm{U} 30$ & 5.2 & 1.9 & 0.97 \\
\hline & $\Delta \mathrm{A} 27-\mathrm{C} 31$ & 12 & 4.3 & 0.98 \\
\hline
\end{tabular}

(ND) Not detectable. $K_{\mathrm{D}}$ values were derived by fitting the increase in BLI signal as a function of RNA concentration using the Octet data analysis software. An asterisk denotes a $K_{\mathrm{D}}$ value in the buffer containing 20\% PEG 200. $R^{2}$ values were calculated from curve fitting.

the secondary structure, giving a virtually identical $K_{\mathrm{D}}$ to the parent molecule $(2.6 \mu \mathrm{M})$ as expected (Table 2; Fig. 2A). As a negative control, we also prepared a construct derived from hsa-pre-miR-21 involving a U1G mutation introduced to facilitate in vitro transcription by T7 RNA polymerase (Fig. $2 \mathrm{~A})$. We attempted to measure the $K_{\mathrm{D}}$ of the hsa-pre-miR21 with respect to folic acid; however, binding was not detectable (Table 2), indicating that the stem-loop structure of hsapre-miR-21 does not bind to folic acid. On the other hand, a mutant of hsa-pre-miR-125a, in which the stem region was replaced with that of pre-miR-21 (Fig. 2B, stemM1), showed a marginally increased $K_{\mathrm{D}}$ value of $4.6 \mu \mathrm{M}$ (Table 2). Similarly, stemM2 containing two compensatory base pairs also showed a marginal increase in $K_{\mathrm{D}}$ to $6.2 \mu \mathrm{M}$ (Table 2; Fig. 2B). We also prepared three mutants containing a single compensatory or G-C mutation near the internal loop of A33-G36 (U22G/A39C, G23C/C38G, and A24U/U37A in Fig. $2 \mathrm{~B}$ ); again these mutants retained virtually the same 

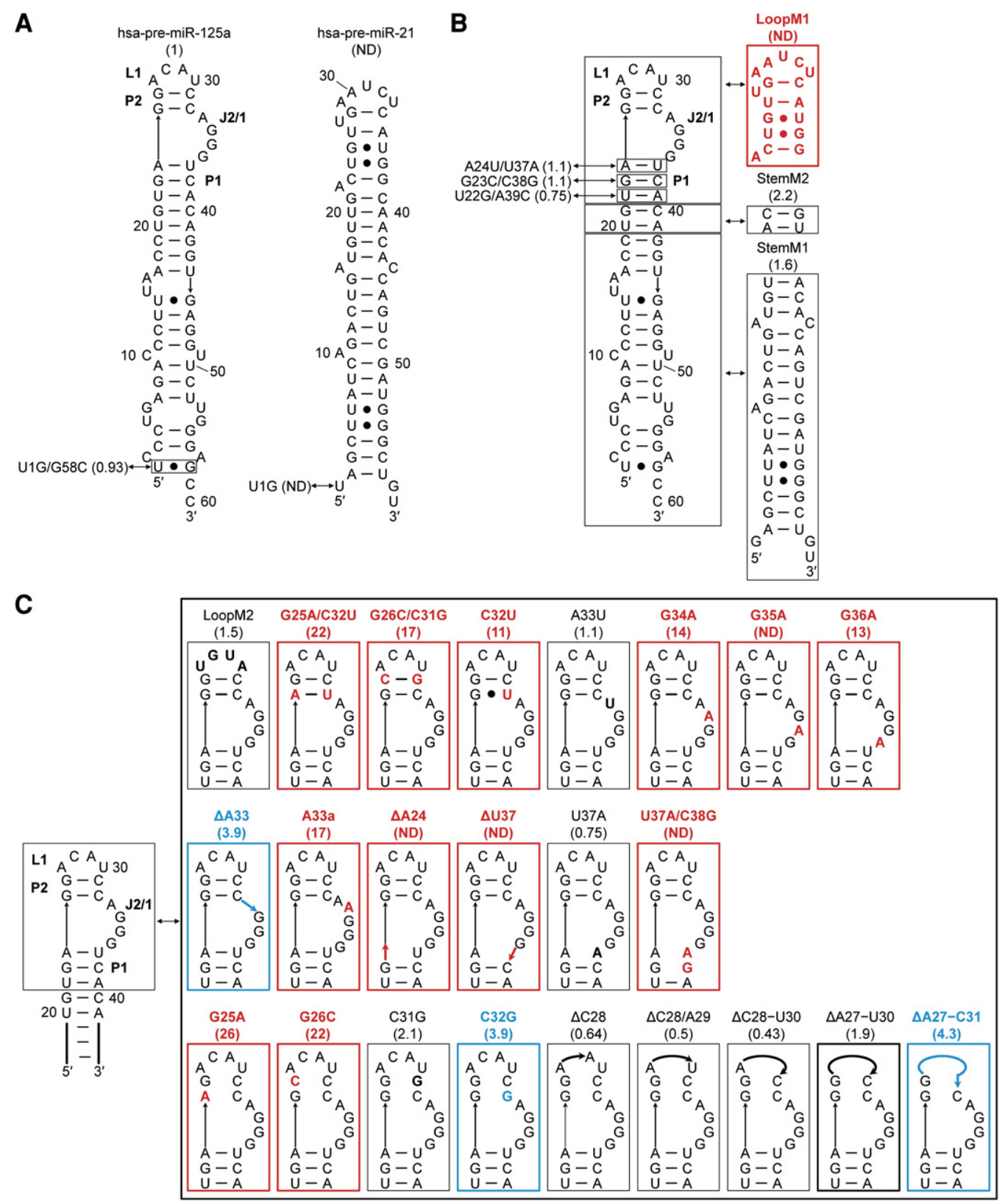

FIGURE 2. Mutants of hsa-pre-miR-125a. The secondary structures of RNAs in this study predicted by mfold (Zuker 2003). Solid lines indicate Watson-Crick base pairs and black dots indicate $G \cdot U$ wobble pairs. The arrows indicate the backbone connectivity from $5^{\prime}$ to $3^{\prime}$. Numbers beside the nucleotides indicate the nucleotide positions. Regions that were replaced by alternative elements are boxed and double-headed arrows indicate the sequence and the structure of mutant RNAs with associated names. Relative $K_{\mathrm{D}}$ values are shown in parentheses and ND means "not detectable." The mutants whose $K_{\mathrm{D}}$ values increased by threefold to 10 -fold are shown in cyan, those whose values increased more than 10-fold are in red. (A) The secondary structures of hsa-pre-miR-125a and hsa-pre-miR-21. hsa-pre-miR-125a consists of four regions: P1 (A1-A24 and U37-C60), P2 (G25-G26 and C31-C32), L1 (A27-U30), and J2/1 (A33-36). (B,C) Mutants of hsa-pre-miR-125a U1G/G58C. Bold lines indicate the stem region (position 1 to 19 and 42 to 60 ) of hsa-pre-miR-125a U1G/G58C.

$K_{\mathrm{D}}$ as the wild type (Table 2). These results indicate that alterations to the stem sequence of hsa-pre-miR-125a have only a negligible negative impact on binding to folic acid.

Since the internal AGGG loop (J2/1), short G-C stem (P2), and ACAU loop (L1) in hsa-pre-miR-125a apparently differ from the inactive LoopM1 derived from hsa-pre-miR-21, we next turned our focus to this region (Fig. 2C). We first re- placed L1 with a tetraloop of UGUA (LoopM2) to see whether the binding ability would be influenced. This mutant was active with a marginal increase in $K_{\mathrm{D}}(=4.2 \mu \mathrm{M}$, Table 2) compared with the wild type $(2.8 \mu \mathrm{M})$. On the other hand, even a single compensatory mutation of the P2 stem (G25A/C32U, G26C/C31G, and C32U) gave appreciable negative impacts on the binding, increasing the $K_{\mathrm{D}}$ by 
approximately 20 -fold. We also prepared a series of point mutants in J2/1 (A33U, G34A, G35A, and G36A), and measured the respective $K_{\mathrm{D}}$ values. Only the A33U mutant retained a wild-type-level activity $\left(K_{\mathrm{D}}=3.0 \mu \mathrm{M}\right)$, while the other mutants were either inactive or 10 - to 20 -fold less active. To further verify the importance of the J2/1 region, we prepared A33-deletion and A33a-insertion mutants; and their $K_{\mathrm{D}}$ increased by fourfold $\left(K_{\mathrm{D}}=11 \mu \mathrm{M}\right)$ and 17 -fold $\left(K_{\mathrm{D}}=48 \mu \mathrm{M}\right)$, respectively. These results suggest that the internal loop plays a critical role in maintaining folic acid binding activity.

To verify the importance of the P1 base pairs near the internal loop, we prepared two deletion mutants and two mutants where the A24-U37 (and G23-C38) base pair(s) was disrupted $(\triangle \mathrm{A} 24, \Delta \mathrm{U} 37, \mathrm{U} 37 \mathrm{~A}$, and U37A/A38G). Neither of the deletion mutants ( $\triangle \mathrm{A} 24$ and $\triangle \mathrm{U} 37)$ retained binding activity to folic acid. The mutant, U37A/A38G, with the disruption of two base pairs in the P1 stem also resulted in loss of function. On the other hand, and to our surprise, the U37A mutant with disruption of a single base pair retained activity $\left(K_{\mathrm{D}}=2.1 \mu \mathrm{M}\right)$.

To obtain further insight into the importance of J2/1, we also made compensatory or disrupting mutants of the P2 stem. The mutants retaining the base pairs of the P2 stem (G25A/C32U, G26C/C31G, and C32U) lost binding ability to folic acid, indicating that the sequence of G25-C32 and G26-C31 is critical for activity. The mutants disrupting the P2 stem (G25A, G26C, and C32G) also largely lost activity, whereas the C31G mutant lost activity by only 2.1 -fold $\left(K_{\mathrm{D}}=6.0 \mu \mathrm{M}\right)$. We also prepared tetraloop-deletion mutants. Three mutants, $\Delta \mathrm{C} 28, \Delta \mathrm{C} 28 / \mathrm{A} 29$, and $\Delta \mathrm{C} 28$-U30, were able to retain near-wild-type activity. Even the $\Delta \mathrm{A} 27-\mathrm{U} 30$ mutant without the tetraloop lost activity by only 1.9 -fold. Further deletion of $\mathrm{C} 31(\triangle \mathrm{A} 27-\mathrm{C} 31)$ gave a reduction in activity of 4.3-fold, retaining an appreciable level of binding activity.

All together, we propose that the bases of hsa-pre-miR125a involved in the interaction with folic acid are the internal AGGG loop (J2/1) and G25-C32/G26-C31 of the stem (P2) region (bases highlighted in red in Fig. 3A), although
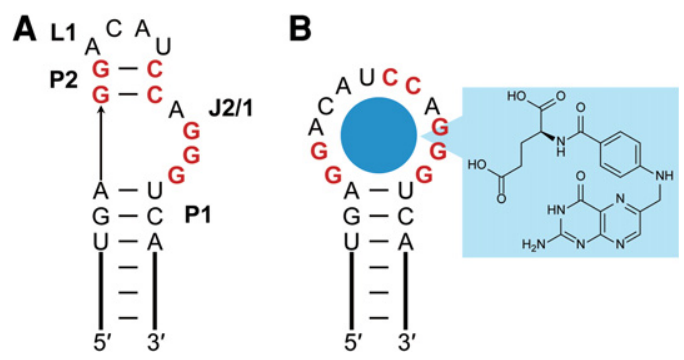

FIGURE 3. Proposed interaction between hsa-pre-miR-125a and folic acid. The bases that are involved in the interaction with folic acid are highlighted in red. (A) The secondary structure of the hsa-pre-miR125a terminal stem-loop region predicted by mfold (Zuker 2003). (B) Schematic illustration of possible adopted folic acid binding structure. Cyan circle indicates folic acid. the formation of the stem may be less critical for binding to folic acid. Probably, upon binding to folic acid, the P2 stem could be broken and adopt an appropriate binding core for folic acid (Fig. 3B).

\section{DISCUSSION}

Recently, RNA aptamers that differ from riboswitches but which bind to metabolites have been discovered in both coding and noncoding RNAs from eukaryotes (Vu et al. 2012; Curtis and Liu 2013, 2014; Baselga-Escudero et al. 2014). These findings suggest that the existence of RNA aptamer elements is not limited to riboswitches and may be widespread in various transcripts including small RNAs in eukaryotes. In this study, we developed an in vitro selection method, referred to as small RNA transcriptomic SELEX, smaRtSELEX, in order to uncover RNA aptamer elements in small RNAs. As a demonstration of smaRt-SELEX, we have here identified a motif existing in the terminal loop of hsa-premiR-125a that appears to interact with folic acid.

In bacteria, the folT riboswitch binding to tetrahydrofolate (THF), which is a reduced form of folic acid, was discovered (Ames et al. 2010) and the structure was solved (Trausch et al. 2011). The folT riboswitch has two ligand binding sites that form a three-way junction and pseudoknot, which are far different from the apical loop of hsa-pre-miR125a. Although the folT riboswitch does not bind to folic acid but to THF, the recognition of the pterin moiety of THF by the folT riboswitch is analogous to nucleobase recognition by RNA aptamers such as purine and preQ1 riboswitches (Trausch et al. 2011). These RNA aptamers recognize the ligands forming base triple-like structures. Thus, it is possible that hsapre-miR125a binds to folic acid in a similar fashion to these RNA aptamers.

A structure search of human miRNA precursors registered in the miRBase (http://www.mirbase.org/) (Kozomara and Griffiths-Jones 2014) has revealed that the loop sequence of pre-miR-125a is completely conserved in mammalian, and is not present in other miRNA precursors (Supplemental Fig. S5); thus, it is widespread in the kingdom but quite unique among the miRNA precursors. It has been shown that pre-miRNAs, including hsa-pre-miR-125a, are generally cleaved by the Drosha-DGCR8 microprocessor complex in the nucleus from long hairpin RNAs, referred to as primary microRNAs (pri-miRNAs) (Cai et al. 2004; Lee et al. 2004; Borchert et al. 2006). During biogenesis of several miRNAs, RNA-binding proteins recognize the terminal loop region of miRNA precursors to up- or down-regulate the processing (Choudhury and Michlewski 2012; Castilla-Liorente et al. 2013). For example, hnRNPA1 (heterogeneous nuclear ribonucleoprotein A1) recognizes the terminal loop to up-regulate pri-miR18a and down-regulate pri-let-7a processing by a microprocessor (Michlewski et al. 2008), and Lin28a binds to the terminal loop of pre-let-7 to change the RNA structure and inhibit the Dicer processing (Nam et al. 2011). Notably, 
the apical stem and terminal loop elements in pri-miR-125a may have a significant contribution to the processing events involving Drosha (Auyeung et al. 2013). Our findings, therefore, may suggest the possibility that folic acid or its intercellular derivatives can regulate the processing of hsa-miR125a like RNA-binding proteins.

The miRNAs in human lymphoblasts (TK-6 cells) whose expression levels dramatically changed with folate-deficient culture medium have been reported (Marsit et al. 2006). Although hsa-miR-125a was not listed in this category of miRNAs, the inherent expression level of hsa-miR-125a in TK-6 cells turned out to be very low (Chaudhry et al. 2013). Therefore, we measured the changes in expression level of hsa-miR-125a in the presence of folic acid using HeLs S3 cells that are known to express hsa-miR-125a. We indeed observed about a $20 \%$ decrease in the hsa-miR$125 \mathrm{a}-5 \mathrm{p}$ expression level after the treatment with $50 \mu \mathrm{M}$ folic acid (Supplemental Fig. S6). This result indicates that folic acid possibly interferes with miR-125a maturation in HeLa S3 cells.

On the other hand, in an in vitro dicing assay (Supplemental Fig. S7), we were unable to observe an increase or decrease in the hsa-pre-miR-125a cleavage by the addition of folic acid. Although we do not have a definitive explanation for this disappointing outcome, it is yet possible that binding of folic acid or its cellular derivatives (vide infra) to the hsapre-miR-125a indirectly modulates other maturation steps such as transcription of pri-miR-125a, cleavage of pri-miR$125 \mathrm{a}$ to pre-miR-125a, and export of pre-miR-125a from the nucleus to the cytoplasm. Clearly, to define the cellular role of folic acid binding to the hsa-pre-miR-125a, more extensive studies are required.

In conclusion, in this report we have described the smaRtSELEX methodology, which enabled us to uncover potential aptamers against a metabolite, folic acid, from a pool of small RNAs in a length range of 10-200 nt. This method is certainly extendable to other metabolites as well as various intracellular macromolecules such as proteins for the discovery of potential aptamers derived from naturally occurring small RNAs, including pre- and pri-miRNAs.

\section{MATERIALS AND METHODS}

\section{Chemical synthesis of Biotin-Phe-CME}

Biotin-Phe-CME was synthesized as previously described (Saito et al. 2001).

\section{In vitro transcription}

The Fx3 + N1 (Futai et al. 2016) and RNAs for BLI analysis were prepared by in vitro transcription with T7 RNA polymerase and purified by denaturing PAGE ( $8 \mathrm{M}$ urea, $1 \times$ TBE, $8 \%$ acrylamide/ bis-acrylamide [19:1]). The primers for preparing transcription templates and RNAs are shown in Supplemental Tables S1, S2. All primers were purchased from Eurofins Genomics K.K. FA1, FA2, and hsa-pre-miR-125a RNAs were purchased from Gene Design, Inc. The concentrations of RNAs were determined by absorbance at $260 \mathrm{~nm}$.

\section{Preparation of dial-Fx}

To avoid the amplification of Fx during construction of the small RNA library, the $3^{\prime}$-end of Fx purified by denaturing PAGE was oxidized to produce a dialdehyde group (named as dial-Fx) under the following conditions: $20 \mu \mathrm{M}$ Fx was incubated with $30 \mathrm{mM} \mathrm{NaIO}_{4}$ on ice for $20 \mathrm{~min}$ and then $2 \%(\mathrm{w} / \mathrm{v}) \mathrm{LiClO}_{4}$ in acetone was added. The mixture was centrifuged at $15,000 \mathrm{~g}$ (room temperature) for 10 min to precipitate dial-Fx. The pellet was rinsed with acetone and centrifuged at $15,000 \mathrm{~g}$ (room temperature) for $3 \mathrm{~min}$ two times, and dissolved in water. The concentrations of RNAs were determined by absorbance at $260 \mathrm{~nm}$.

\section{Cell cultures for construction of small RNA library}

BeWo cells (RIKEN Cell Bank, code RCB1644) were grown in Ham's F-12 medium (17458-65, Nacalai Tesque, Inc.) supplemented with $100 \mathrm{unit} / \mathrm{mL}$ penicillin, $100 \mu \mathrm{g} / \mathrm{mL}$ streptomycin (15140122, Thermo Fisher Scientific), and $10 \%$ fetal bovine serum (10437-010, Thermo Fisher Scientific) in an incubator with 5\% $\mathrm{CO}_{2}$ at $37^{\circ} \mathrm{C}$. HuH-7, VMRC-RCW, NEC14, HuO-3N1, and RAJI Cells (RIKEN Cell Bank, code RCB1942, RCB1963, RCB0490, RCB2104, and RCB1647) were grown in RPMI 1640 medium (30264-85, Nacalai Tesque, Inc.) supplemented with $100 \mathrm{unit} / \mathrm{mL}$ penicillin, $100 \mu \mathrm{g} / \mathrm{mL}$ streptomycin (15140-122, Thermo Fisher Scientific), and 10\% fetal bovine serum (10437-010, Thermo Fisher Scientific) in an incubator with $5 \% \mathrm{CO}_{2}$ at $37^{\circ} \mathrm{C}$. MCF7 cells (RIKEN Cell Bank, code RCB1940) were grown in MEM (21442-25, Nacalai Tesque, Inc.) supplemented with 100 unit/mL penicillin, $100 \mu \mathrm{g} / \mathrm{mL}$ streptomycin (15140-122, Thermo Fisher Scientific), $0.1 \mathrm{mM}$ nonessential amino acids (M71455, Sigma-Aldrich), $1 \mathrm{mM}$ sodium pyruvate (S8636, Sigma-Aldrich) and 10\% fetal bovine serum (10437-010, Thermo Fisher Scientific) in an incubator with $5 \% \mathrm{CO}_{2}$ at $37^{\circ} \mathrm{C}$. HeLa S3 cells (JCRB Cell Bank, JCRB0713) were grown in DMEM (08458-45, Nacalai Tesque) supplemented with $100 \mathrm{unit} / \mathrm{mL}$ penicillin, $100 \mu \mathrm{g} / \mathrm{mL}$ streptomycin (15140-122, Thermo Fisher Scientific) and 10\% fetal bovine serum (10437-010, Thermo Fisher Scientific) in an incubator with 5\% $\mathrm{CO}_{2}$ at $37^{\circ} \mathrm{C}$.

\section{Construction of the rRNA/tRNA-depleted human small RNA library}

Once cells reached $\sim 20 \%$ confluence, the media were removed and ISOGEN II (311-07361, NIPPON GENE) was added to dissolve cells. Small RNAs (10-200 nt) were isolated according to the manufacturer's protocol. The concentrations were determined by absorbance at $260 \mathrm{~nm}$.

Small RNAs extracted from each cell line were mixed at equal ratios and $10 \mu \mathrm{g}$ of small RNAs were treated with the RiboMinus Eukaryote kit (A10837-08, Thermo Fisher Scientific) according to the manufacturer's protocol. Ribosomal RNA-depleted small RNAs were separated into a 10-60 nt fraction and a 60-200 nt fraction by denaturing PAGE ( $8 \mathrm{M}$ urea, $1 \times \mathrm{TBE}, 8 \%$ acrylamide/bisacrylamide [19:1]). tRNAs in the 60-200 nt fraction of small 
RNAs were removed under the following conditions: A mixture of $48 \mu \mathrm{L}$ of $73.3 \mathrm{ng} / \mu \mathrm{L} 60-200 \mathrm{nt}$ fraction of small RNAs and 33.3 $\mu \mathrm{M}$ dial-Fx in $166.7 \mathrm{mM}$ HEPES-KOH ( $\mathrm{pH}$ 7.5) was heated at $95^{\circ} \mathrm{C}$ for $2 \mathrm{~min}$ and cooled to room temperature over $5 \mathrm{~min}$. Sixteen microliters of $3 \mathrm{M} \mathrm{MgCl}_{2}$ were added, and the mixture was transferred to an ice bath; $16 \mu \mathrm{L}$ of $25 \mathrm{mM}$ Biotin-Phe-CME in DMSO was added, and the mixture was incubated on ice for 2 h. After $2 \mathrm{~h}$ incubation, $8 \mu \mathrm{L}$ of $3 \mathrm{M} \mathrm{NaCl}$ and $220 \mu \mathrm{L}$ of ethanol were added, and then precipitated. To capture biotin-Phe-tRNAs, the RNA was dissolved with $120 \mu \mathrm{L}$ of Sav (Streptavidin) binding buffer ( $5 \mathrm{mM}$ HEPES-KOH [pH 7.5], $500 \mu \mathrm{M}$ EDTA, $1 \mathrm{M} \mathrm{NaCl}$ and $0.1 \%$ tween-20) and then mixed with $1.2 \mathrm{mg}$ of Dynabeads M-280 Streptavidin (11205D, Thermo Fisher Scientific), which were prewashed with Sav wash buffer (5 mM Tris- $\mathrm{HCl}$ [ $\mathrm{pH} 7.5]$, $500 \mu \mathrm{M}$ EDTA and $1 \mathrm{M} \mathrm{NaCl}$ ) three times before use, Sav solution A $(0.1 \mathrm{M} \mathrm{NaOH}$ and $50 \mathrm{mM} \mathrm{NaCl})$ two times, and $0.1 \mathrm{M} \mathrm{NaCl}$ one time. After $15 \mathrm{~min}$ incubation using a rotary shaker at room temperature, the supernatant was recovered and precipitated with ethanol. For the second aminoacylation, the RNA was dissolved in $32 \mu \mathrm{L}$ of $125 \mathrm{mM}$ HEPES-KOH ( $\mathrm{pH} 7.5$ ) with $0.75 \mathrm{M} \mathrm{MgCl}_{2}$ and incubated at room temperature for $5 \mathrm{~min}$. The mixture was then placed on ice and $8 \mu \mathrm{L}$ of $25 \mathrm{mM}$ Biotin-Phe-CME was added. After $2 \mathrm{~h}$ incubation on ice, $48 \mu \mathrm{L}$ of $500 \mathrm{mM} \mathrm{NaCl}$ and $220 \mu \mathrm{L}$ of ethanol were added. RNAs were precipitated and dissolved in $80 \mu \mathrm{L}$ of Sav binding buffer. To capture biotin-Phe-tRNAs, the same procedure described above was performed using $800 \mu \mathrm{g}$ of beads. Supernatant was precipitated with ethanol and dissolved in $16 \mu \mathrm{L}$ of $125 \mathrm{mM}$ HEPES$\mathrm{KOH}\left(\mathrm{pH} 7.5\right.$ ) with $0.75 \mathrm{M} \mathrm{MgCl}_{2}$ and incubated at room temperature for $5 \mathrm{~min}$. The mixture was then placed on ice, and $4 \mu \mathrm{L}$ of 25 $\mathrm{mM}$ Biotin-Phe-CME was added. After $2 \mathrm{~h}$ incubation on ice, $68 \mu \mathrm{L}$ of $500 \mathrm{mM} \mathrm{NaCl}$ and $220 \mu \mathrm{L}$ of ethanol were added. RNAs were precipitated and dissolved in $40 \mu \mathrm{L}$ Sav binding buffer. To capture biotin-Phe-tRNAs, the same procedure described above was performed using $400 \mu \mathrm{g}$ of beads. The supernatant was precipitated with ethanol and dissolved in water. The concentrations were determined by absorbance at $260 \mathrm{~nm}$.

Dial-Fx in the tRNA-depleted small RNA fraction was removed by denaturing PAGE ( $8 \mathrm{M}$ urea, $1 \times \mathrm{TBE}, 8 \%$ acrylamide/bis-acrylamide [19.1]). The entire amount of the rRNA/tRNA-depleted small RNA fraction and the 10-60 nt fraction were mixed and used for preparation of the cDNA library.

\section{Construction of the cDNA library from the rRNA/ tRNA-depleted human small RNA library}

The 3 -adaptor (purchased from Integrated DNA Technologies) and $5^{\prime}$-adaptor (purchased from Japan Bio Service) were purified by denaturing PAGE ( $8 \mathrm{M}$ urea, $1 \times$ TBE, 20\% acrylamide/bis-acrylamide [19.1]) before use. For ligation of the $3^{\prime}$-adaptor, a mixture of $6.67 \mu \mathrm{L} / 70 \mathrm{ng} / \mu \mathrm{L}$ of $\mathrm{rRNA} / \mathrm{tRNA}$-depleted human small RNA library, $15 \mu \mathrm{M}$ 3'-adaptor, 25\% (v/v) PEG8000, 40 U/ $\mu \mathrm{L}$ T4 RNA ligase 2 truncated (M0242S, New England BioLabs), and $1 \times$ T4 RNA ligase 2 truncated reaction buffer was incubated at $16^{\circ} \mathrm{C}$ for 12 h. After incubation, RNA was extracted with phenol-chloroform and precipitated with ethanol. Nonreacted 3 -adaptor was removed by denaturing PAGE ( $8 \mathrm{M}$ urea, $1 \times \mathrm{TBE}, 8 \%$ acrylamide/bis-acrylamide [19.1]). The RNA library ligated with the 3 -adaptor was treated with $\mathrm{NaIO}_{4}$, according to the protocol described above, in order to avoid the ligation of the contaminated RNA library not li- gated with the $3^{\prime}$-adaptor in the next step. For ligation of the $5^{\prime}$ adaptor, $10 \mu \mathrm{L}$ mixture of the entire amount of the RNA library ligated with the $3^{\prime}$-adaptor, $20 \mu \mathrm{M} 5^{\prime}$-adaptor, $15 \%$ (v/v) PEG8000, $30 \mathrm{U} / \mu \mathrm{L}$ T4 RNA ligase 1 (M0204S, New England BioLabs), and $1 \times$ reaction buffer attached with T4 RNA ligase 1 was incubated at $37^{\circ} \mathrm{C}$ for $30 \mathrm{~min}$ and then at $16^{\circ} \mathrm{C}$ for $12 \mathrm{~h}$. After the incubation, RNA was extracted with phenol-chloroform and precipitated with ethanol. The nonreacted $5^{\prime}$-adaptor was removed by denaturing PAGE ( 8 M urea, $1 \times$ TBE, $8 \%$ acrylamide/bis-acrylamide [19.1]). The RNA library ligated with $3^{\prime} / 5^{\prime}$-adaptors was converted to cDNA by reverse transcription and PCR using primers sele- 1 and sele-2 and PrimeScript One Step RT-PCR Kit Ver.2 (RR055A, TaKaRa), and the resulting cDNA was purified by Native-PAGE $(1 \times$ TBE, $8 \%$ acrylamide/bis-acrylamide [19.1]).

\section{Immobilization of folic acid onto the magnetic beads}

Magnetic beads whose surface was modified with hydroxyl groups (FG-beads, TAS8848 N1120, Tamagawa Seiki Co., Ltd.) were used for immobilization of folic acid. FG-beads were suspended in $N$, $\mathrm{N}$-dimethylformamide (DMF, 10344-00, KANTO CHEMICAL) at $5 \mu \mathrm{g} / \mu \mathrm{L}$ and washed with DMF three times. FG-beads $(5 \mu \mathrm{g} / \mu \mathrm{L})$ were incubated at $25^{\circ} \mathrm{C}$ for $24 \mathrm{~h}$ with $10 \mathrm{mM}$ folic acid (16221-91, Nacalai Tesque) in DMF in the presence of $10 \mathrm{mM}$ EDC (1-ethyl3-(3-dimethylaminopropyl) carbodiimide hydrochloride, 1502286, Nacalai Tesque) and $10 \%(\mathrm{v} / \mathrm{v})$ triethylamine (202-02641, WAKO). Thereafter, the folic acid-immobilized beads were washed with DMF three times and suspended in DMF at $10 \mu \mathrm{g} / \mu \mathrm{L}$.

\section{smaRt-SELEX}

The cDNA library was transcribed into an RNA library by in vitro transcription with T7 RNA polymerase and purified by denaturing PAGE ( 8 M urea, $1 \times$ TBE, $8 \%$ acrylamide/bis-acrylamide [19.1]). A $10 \mu \mathrm{L}$ sample of $510 \mathrm{ng} / \mu \mathrm{L}$ RNA library and $1 \times$ selection buffer $(50$ $\mathrm{mM}$ HEPES-KOH [pH 7.5], $300 \mathrm{mM} \mathrm{KCl,} 5 \mathrm{mM} \mathrm{MgCl}_{2}$ and $0.05 \%$ tween-20) was mixed with hydroxylated FG-beads which had been prewashed with $1 \times$ selection buffer three times before use, and this mixture was incubated on a rotary shaker at $4^{\circ} \mathrm{C}$ for $30 \mathrm{~min}$ (the "preclear" process). After incubation, the supernatant was added to folic acid-immobilized beads which had been washed with $1 \times$ selection buffer three times before use, and this mixture was incubated using a rotary shaker at $4^{\circ} \mathrm{C}$ for $1 \mathrm{~h}$. After incubation, the supernatant was discarded and the beads were washed with $100 \mu \mathrm{L}$ of $1 \times$ selection buffer (the "wash" process). The beads were suspended in 1 $\mathrm{mM}$ folic acid in $1 \times$ selection buffer and incubated using a rotary shaker at $4^{\circ} \mathrm{C}$ for $30 \mathrm{~min}$ to elute the RNAs binding to the folic acid-immobilized beads. The supernatant was recovered and this elution cycle repeated three times. All of the supernatants were mixed and precipitated with ethanol. The pellet was dissolved in $10 \mu \mathrm{L}$ of water.

To quantify the amount of recovered RNAs from beads, quantitative RT-PCR was performed as follows: $0.5 \%$ of recovered RNAs were mixed with $10 \mu \mathrm{L}$ of RT mix $(500 \mu \mathrm{M}$ dNTP, $5 \mu \mathrm{M}$ primer sele-2, $8 \mathrm{U} / \mu \mathrm{L}$ M-MLV reverse transcriptase [M1701, Promega K. $\mathrm{K}$.] and $1 \times \mathrm{M}-\mathrm{MLV}$ reverse transcriptase reaction buffer), and this mixture was incubated at $50^{\circ} \mathrm{C}$ for $1 \mathrm{~h}$. After incubation, $1 \mu \mathrm{L}$ of reverse transcription reaction solution was mixed with $19 \mu \mathrm{L}$ of qPCR mix (5 $\mu \mathrm{M}$ primer sele-1, $5 \mu \mathrm{M}$ primer sele-2 $10 \mathrm{mM}$ Tris- 
$\mathrm{HCl}$ [pH 9.0], $50 \mathrm{mM} \mathrm{KCl,} \mathrm{0.1 \%} \mathrm{Triton-X100,} 2.5 \mathrm{mM} \mathrm{MgCl}_{2}, 0.25$ mM dNTP, 1/1,000,000 SYBR Green I [50512, LONZA], Taq DNA polymerase) and qPCR was performed using a LightCycler1.5 thermocycler (Roche Diagnostics K.K.) at $94^{\circ} \mathrm{C}\left(20^{\circ} \mathrm{C} / \mathrm{sec}\right)$ for $1 \mathrm{~min}$, followed by 35 cycles of $94^{\circ} \mathrm{C}$ for $10 \mathrm{sec}\left(20^{\circ} \mathrm{C} / \mathrm{sec}\right), 51^{\circ} \mathrm{C}$ for 10 $\sec \left(20^{\circ} \mathrm{C} / \mathrm{sec}\right)$ and $72^{\circ} \mathrm{C}$ for $30 \mathrm{sec}\left(0.5^{\circ} \mathrm{C} / \mathrm{sec}\right)$ to measure $C_{\mathrm{p}}$ values.

The remaining recovered RNA not used for qPCR was mixed with RT mix and this mixture was incubated at $50^{\circ} \mathrm{C}$ for $1 \mathrm{~h}$. After the incubation, all of the reverse transcription reaction solution was mixed with $200 \mu \mathrm{L}$ of qPCR mix without SYBR Green I and DNA was amplified by PCR for $\mathrm{C}_{\mathrm{p}}+2$ cycles of $94^{\circ} \mathrm{C}$ for $10 \mathrm{sec}, 51^{\circ} \mathrm{C}$ for $10 \mathrm{sec}$, and $72^{\circ} \mathrm{C}$ for $30 \mathrm{sec}$. DNA was extracted with phenolchloroform and precipitated with ethanol, and then used for the next round of selection.

For the first round of selection, the preclear process was not performed, the wash process was performed once, and $200 \mu \mathrm{g}$ of beads were used. For the second round of selection, the preclear process was performed once, the wash process was performed once, and $100 \mu \mathrm{g}$ of beads were used. For the third round of selection, the preclear process was performed once, the wash process was repeated three times, and $100 \mu \mathrm{g}$ of beads were used. For the fourth round of selection, the preclear process was performed once, the wash process was repeated three times, and $20 \mu \mathrm{g}$ of beads were used.

\section{Sequencing}

The cDNAs of the tRNA-depleted human small RNA library and RNAs after smaRt-SELEX were TA cloned into pGEM-T Easy Vectors (A1360, Promega K.K.). These vectors were used to transform E. coli DH5a cells in LB medium with $100 \mu \mathrm{g} / \mathrm{mL}$ ampicillin. Cloned cDNAs were amplified by colony-PCR using primers seq1 and seq-2, and sequenced by FASMAC Co., Ltd.

To annotate the sequenced RNAs, BLAST searches (Altschul et al. 1990) using the NCBI human genomic plus transcript database (http://blast.ncbi.nlm.nih.gov/Blast.cgi), fRNA database (Mituyama et al. 2009) (http://www.ncrna.org/frnadb/), genomic tRNA database (Chan and Lowe 2009) (http://gtrnadb.ucsc.edu/), snoRNABase (Lestrade and Weber 2006) (https://www-snorna. biotoul.fr/), and miRbase (Kozomara and Griffiths-Jones 2014) (http://www.mirbase.org/) were performed.

\section{Biolayer interferometry (BLI)}

Binding of RNAs to folic acid was measured using the Octet RED96 biolayer interferometry (BLI) instrument (ForteBio, Inc.) and all measurements were conducted at $30^{\circ} \mathrm{C}$ with an agitation rate of $1000 \mathrm{rpm}$. Folic acid was immobilized onto the amine reactive second-generation (AR2G) biosensor from ForteBio as follows: The AR2G sensors were pre-wet for more than $10 \mathrm{~min}$ in water prior to use. Each sensor was equilibrated in water for $3 \mathrm{~min}$ and then activated with EDC/NHS solution $(200 \mathrm{mM}$ EDC and $50 \mathrm{mM}$ $N$-hydroxysuccinimide [NHS, A00013, Watanabe Chemical Industries] in water) for $10 \mathrm{~min}$. The activated sensors were modified to contain free amine groups by incubating with EDA solution (100 mM ethylenediamine [15020-22, Nacalai Tesque, Inc.], and $10 \mathrm{mM}$ boric acid buffer [pH 8.5] and $1 \mathrm{M} \mathrm{NaCl}$ ) for $150 \mathrm{sec}$, and then quenched with $1 \mathrm{M}$ ethanolamine (E6133, Sigma-Aldrich, $\mathrm{pH} 8.5$ adjusted by $\mathrm{KOH}$ ) for $3 \mathrm{~min}$. The amine group-immobilized sensors were equilibrated with $250 \mathrm{mM}$ phosphate buffer ( $\mathrm{pH} 7.0$ ) for $3 \mathrm{~min}$ and then folic acid was immobilized by incubating with FA/EDC/NHS/Phos solution (20 mM folic acid, $200 \mathrm{mM}$ EDC, 50 $\mathrm{mM}$ NHS and $250 \mathrm{mM}$ phosphate buffer [ $\mathrm{pH} 7.0]$ ) for $20 \mathrm{~min}$. The folic acid-immobilized sensors were incubated with water for $3 \mathrm{~min}$. Reference sensors for the binding analysis were prepared following the same protocols described above using EDC/NHS/Phos solution (200 mM EDC, $50 \mathrm{mM}$ NHS and $250 \mathrm{mM}$ phosphate buffer [pH 7.0]) instead of FA/EDC/NHS/Phos solution.

Binding of RNA to folic acid was measured as follows: folic acidimmobilized sensors or reference sensors were pre-wet for more than $10 \mathrm{~min}$ in Octet buffer (50 mM HEPES-KOH [pH 7.5], 300 $\mathrm{mM} \mathrm{KCl}, 50 \mathrm{mM} \mathrm{MgCl}_{2}, 0.05 \%$ tween-20) prior to use. The sensors were equilibrated in Octet buffer for $3 \mathrm{~min}$, then incubated in Octet buffer for $1 \mathrm{~min}$ to generate a baseline. As an association step, the sensors were incubated in RNA dissolved in Octet buffer. After this association step, the sensors were incubated in Octet buffer as a dissociation step. The sensors were regenerated by incubating in R buffer (20 mM EDTA and 0.05\% tween-20) for 10 sec 5 times. The ForteBio Data Analysis Octet software was used to perform 1:1 steady-state analysis. For each RNA, six to eight concentrations were used, from $200 \mathrm{nM}$ to $240 \mu \mathrm{M}$ (depending on the affinity of each RNA). To confirm the immobilization of folic acid onto the sensor, anti-folic acid antibody (sc-66160, Santa Cruz Biotechnology) was used instead of RNA.

\section{Cell cultures and RNA extraction for quantification of miRNA expression}

HeLaS3 cells (JCRB Cell Bank, JCRB0713) were grown in RPMI1640 (11875-093, Gibco) supplemented with $100 \mu \mathrm{g} / \mathrm{mL}$ penicillin, 100 unit/mL streptomycin (15140-122, Life Technologies), and $10 \%$ dialyzed fetal bovine serum (SH30079.03 Thermo Scientific) in an incubator with $5 \% \mathrm{CO}_{2}$ at $37^{\circ} \mathrm{C}$. Cells were spread onto a 6-well plate (3506, Corning) at a density of $2 \times 10^{5}$ cells/well and cultured $53 \mathrm{~h}$ in an incubator with $5 \% \mathrm{CO}_{2}$ at $37^{\circ} \mathrm{C}$. To prepare the media containing a high concentration of folic acid, the media were replaced with RPMI1640 (11875-093, Gibco) supplemented with $100 \mu \mathrm{g} / \mathrm{mL}$ penicillin, $100 \mathrm{unit} / \mathrm{mL}$ streptomycin (15140122, Life Technologies), 10\% (v/v) dialyzed fetal bovine serum (SH30079.03 Thermo Scientific), and 1\% (v/v) folic acid solution diluted in PBS. As a control experiment, PBS was added to the media instead of folic acid. Folic acid solution was prepared as follows: 500 $\mathrm{mM} \mathrm{KOH}$ was added to a final concentration of $200 \mathrm{mM}$ folic acid, and diluted by PBS to a final concentration of $10 \mathrm{mM}$. This solution was filtered with $0.2 \mu \mathrm{m}$ membrane filter (SLLGH04N, Millipore), and diluted with PBS to the desired concentration. After the replacement of the media, cells were cultured $1 \mathrm{~h}$ in an incubator with 5\% $\mathrm{CO}_{2}$ at $37^{\circ} \mathrm{C}$. Then the media were removed and $1 \mathrm{~mL}$ ISOGEN II (311-07361, NIPPON GENE) was added to dissolve cells. Total RNAs were isolated according to the manufacturer's protocol. The concentrations were determined by absorbance at $260 \mathrm{~nm}$.

\section{Quantification of miRNA by RT-qPCR}

To quantify mature miRNAs by reverse transcription-quantitative polymerase chain reaction (RT-qPCR), Taqman MicroRNA Reverse Transcription Kit (4366596, Life Technologies) was used for reverse transcription, and Taqman MicroRNA Assays (Life Technologies) and Taqman Universal Master Mix II no UNG (4440040, Life 
Technologies) were used for qPCR. The reverse transcription was performed following the manufacturer's protocol and the final concentration of total RNAs in the reverse transcription reaction was $0.667 \mathrm{ng} / \mu \mathrm{L}$. A total of $1.33 \mu \mathrm{L}$ of $\mathrm{cDNA}$ was used in a subsequent qPCR. PCR was performed using LightCycler Nano (Roche) at $95^{\circ} \mathrm{C}\left(2^{\circ} \mathrm{C} / \mathrm{sec}\right)$ for $10 \mathrm{~min}$, followed by 50 cycles of $95^{\circ} \mathrm{C}$ for 15 $\sec \left(2^{\circ} \mathrm{C} / \mathrm{sec}\right)$ and $60^{\circ} \mathrm{C}$ for $60 \mathrm{sec}\left(1.6^{\circ} \mathrm{C} / \mathrm{sec}\right)$. The fold change in the miRNA level was calculated by $2^{-\Delta \Delta \mathrm{Cq}}$, where $\Delta \mathrm{Cq}=\mathrm{Cq}$ (miRNA) - Cq (U6 snRNA), and $\Delta \Delta \mathrm{Cq}=\Delta \mathrm{Cq}$ (treated sample) $-\triangle \mathrm{Cq}$ (control sample).

\section{SUPPLEMENTAL MATERIAL}

Supplemental material is available for this article.

\section{ACKNOWLEDGMENTS}

We thank Dr. Y. Tomari for providing a plasmid encoding SBPDicer1. We thank Dr. T. Passioura for proofreading the manuscript. This work was supported by Grants-in-Aid for Research (S) (23220204), Japan Society for the Promotion of Science (JSPS), and Japan Science and Technology (JST) agency, CREST-Molecular Technology, to H.S. N.T. is supported by Grants-in-Aid for JSPS Fellows (24-8188). T.K. is supported by a JSPS Grant-in-Aid for Challenging Exploratory Research (26560429).

Received May 27, 2016; accepted September 12, 2016.

\section{REFERENCES}

Altschul SF, Gish W, Miller W, Myers EW, Lipman DJ. 1990. Basic local alignment search tool. J Mol Biol 215: 403-410.

Ames TD, Rodionov DA, Weinberg Z, Breaker RR. 2010. A eubacterial riboswitch class that senses the coenzyme tetrahydrofolate. Chem Biol 17: 681-685.

Auyeung VC, Ulitsky I, McGeary SE, Bartel DP. 2013. Beyond secondary structure: primary-sequence determinants license pri-miRNA hairpins for processing. Cell 152: 844-858.

Baselga-Escudero L, Blade C, Ribas-Latre A, Casanova E, Suarez M, Torres JL, Salvado MJ, Arola L, Arola-Arnal A. 2014. Resveratrol and EGCG bind directly and distinctively to miR-33a and miR122 and modulate divergently their levels in hepatic cells. Nucleic Acids Res 42: 882-892.

Borchert GM, Lanier W, Davidson BL. 2006. RNA polymerase III transcribes human microRNAs. Nat Struct Mol Biol 13: 1097-1101.

Cai XZ, Hagedorn CH, Cullen BR. 2004. Human microRNAs are processed from capped, polyadenylated transcripts that can also function as mRNAs. RNA 10: 1957-1966.

Castilla-Liorente V, Nicastro G, Ramos A. 2013. Terminal loop-mediated regulation of miRNA biogenesis: selectivity and mechanisms. Biochem Soc Trans 41: 861-865.

Chan PP, Lowe TM. 2009. GtRNAdb: a database of transfer RNA genes detected in genomic sequence. Nucleic Acids Res 37: D93-D97.

Chaudhry MA, Omaruddin RA, Brumbaugh CD, Tariq MA, Pourmand N. 2013. Identification of radiation-induced microRNA transcriptome by next-generation massively parallel sequencing. $J$ Radiat Res 54: 808-822.

Chen L, Yun SW, Seto J, Liu W, Toth M. 2003. The fragile X mental retardation protein binds and regulates a novel class of mRNAs containing U rich target sequences. Neuroscience 120: 1005-1017.

Choudhury NR, Michlewski G. 2012. Terminal loop-mediated control of microRNA biogenesis. Biochem Soc Trans 40: 789-793.
Curtis E, Liu D. 2013. Discovery of widespread GTP-binding motifs in genomic DNA and RNA. Chem Biol 20: 521-532.

Curtis EA, Liu DR. 2014. A naturally occurring, noncanonical GTP aptamer made of simple tandem repeats. RNA Biol 11: 682-692.

Dobbelstein M, Shenk T. 1995. In vitro selection of RNA ligands for the ribosomal L22 protein associated with Epstein-Barr virus-expressed RNA by using randomized and cDNA-derived RNA libraries. J Virol 69: 8027-8034.

Ellington A, Szostak J. 1990. In vitro selection of RNA molecules that bind specific ligands. Nature 346: 818-822.

Fujimoto Y, Nakamura Y, Ohuchi S. 2012. HEXIM1-binding elements on mRNAs identified through transcriptomic SELEX and computational screening. Biochimie 94: 1900-1909.

Futai K, Terasaka N, Katoh T, Suga H. 2016. tRid, an enabling method to isolate previously inaccessible small RNA fractions. Methods 106: 105-111.

Huttenhofer A, Brosius J, Bachellerie JP. 2002. RNomics: identification and function of small, non-messenger RNAs. Curr Opin Chem Biol 6: $835-843$.

Jiang R, Hu FB, Giovannucci EL, Rimm EB, Stampfer MJ, Spiegelman D, Rosner BA, Willett WC. 2003. Joint association of alcohol and folate intake with risk of major chronic disease in women. Am J Epidemiol 158: 760-771.

Koppers-Lalic D, Hackenberg M, Bijnsdorp IV, van Eijndhoven MA, Sadek P, Sie D, Zini N, Middeldorp JM, Ylstra B, de Menezes RX, et al. 2014. Nontemplated nucleotide additions distinguish the small RNA composition in cells from exosomes. Cell Rep 8: 1649-1658.

Kozomara A, Griffiths-Jones S. 2014. miRBase: annotating high confidence microRNAs using deep sequencing data. Nucleic Acids Res 42: D68-D73.

Lee Y, Kim M, Han JJ, Yeom KH, Lee S, Baek SH, Kim VN. 2004. MicroRNA genes are transcribed by RNA polymerase II. EMBO J 23: 4051-4060.

Lee YS, Shibata Y, Malhotra A, Dutta A. 2009. A novel class of small RNAs: tRNA-derived RNA fragments (tRFs). Genes Dev 23: 26392649.

Lestrade L, Weber MJ. 2006. snoRNA-LBME-db, a comprehensive database of human H/ACA and C/D box snoRNAs. Nucleic Acids Res 34: D158-D162.

Marsit CJ, Eddy K, Kelsey KT. 2006. MicroRNA responses to cellular stress. Cancer Res 66: 10843-10848.

Melse-Boonstra A, West CE, Katan MB, Kok FJ, Verhoef P. 2004. Bioavailability of heptaglutamyl relative to monoglutamyl folic acid in healthy adults. Am J Clin Nutr 79: 424-429.

Michlewski G, Guil S, Semple CA, Caceres JF. 2008. Posttranscriptional regulation of miRNAs harboring conserved terminal loops. Mol Cell 32: 383-393.

Mituyama T, Yamada K, Hattori E, Okida H, Ono Y, Terai G, Yoshizawa A, Komori T, Asai K. 2009. The Functional RNA Database 3.0: databases to support mining and annotation of functional RNAs. Nucleic Acids Res 37: D89-D92.

Mulinare J, Cordero JF, Erickson JD, Berry RJ. 1988. Periconceptional use of multivitamins and the occurrence of neural tube defects. JAMA 260: 3141-3145.

Nam Y, Chen C, Gregory RI, Chou JJ, Sliz P. 2011. Molecular basis for interaction of let-7 microRNAs with Lin28. Cell 147: 1080-1091.

Pan T, Uhlenbeck OC. 1993. Circularly permuted DNA, RNA and proteins - a review. Gene 125: 111-114.

Saito H, Kourouklis D, Suga H. 2001. An in vitro evolved precursor tRNA with aminoacylation activity. EMBO J 20: 1797-1806.

Serganov A, Nudler E. 2013. A decade of riboswitches. Cell 152: 17-24.

Singer B, Shtatland T, Brown D, Gold L. 1997. Libraries for genomic SELEX. Nucleic Acids Res 25: 781-786.

Stoltenburg R, Reinemann C, Strehlitz B. 2007. SELEX-a (r)evolutionary method to generate high-affinity nucleic acid ligands. Biomol Eng 24: $381-403$. 


\section{Terasaka et al.}

Trausch JJ, Ceres P, Reyes FE, Batey RT. 2011. The structure of a tetrahydrofolate-sensing riboswitch reveals two ligand binding sites in a single aptamer. Structure 19: 1413-1423.

Tuerk C, Gold L. 1990. Systematic evolution of ligands by exponential enrichment: RNA ligands to bacteriophage T4 DNA polymerase. Science 249: 505-510.

$\mathrm{Vu}$ MM, Jameson NE, Masuda SJ, Lin D, Larralde-Ridaura R, Luptak A. 2012. Convergent evolution of adenosine aptamers spanning bacterial, human, and random sequences revealed by structure-based bioinformatics and genomic SELEX. Chem Biol 19: $1247-1254$.

Weinberg Z, Barrick JE, Yao Z, Roth A, Kim JN, Gore J, Wang JX, Lee ER, Block KF, Sudarsan N, et al. 2007. Identification of 22 candidate structured RNAs in bacteria using the CMfinder comparative genomics pipeline. Nucleic Acids Res 35: 4809-4819.

Weinberg Z, Wang JX, Bogue J, Yang J, Corbino K, Moy RH, Breaker RR. 2010. Comparative genomics reveals 104 candidate structured RNAs from bacteria, archaea, and their metagenomes. Genome Biol 11: R31.

Wishart DS, Jewison T, Guo AC, Wilson M, Knox C, Liu YF, Djoumbou Y, Mandal R, Aziat F, Dong E, et al. 2013. HMDB 3.0-The Human Metabolome Database in 2013. Nucleic Acids Res 41: D801-D807.

Zimmermann B, Bilusic I, Lorenz C, Schroeder R. 2010. Genomic SELEX: a discovery tool for genomic aptamers. Methods 52: 125-132.

Zuker M. 2003. Mfold web server for nucleic acid folding and hybridization prediction. Nucleic Acids Res 31: 3406-3415. 

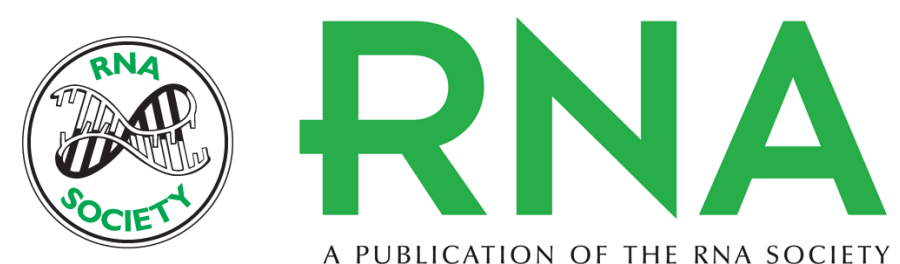

A PUBLICATION OF THE RNA SOCIETY

\section{A human microRNA precursor binding to folic acid discovered by small RNA transcriptomic SELEX}

Naohiro Terasaka, Kazuki Futai, Takayuki Katoh, et al.

RNA 2016 22: 1918-1928 originally published online October 21, 2016

Access the most recent version at doi:10.1261/rna.057737.116

\section{Supplemental http://rnajournal.cshlp.org/content/suppl/2016/10/21/rna.057737.116.DC1 Material}

References This article cites 43 articles, 10 of which can be accessed free at: http://rnajournal.cshlp.org/content/22/12/1918.full.html\#ref-list-1

Creative This article is distributed exclusively by the RNA Society for the first 12 months after the Commons License full-issue publication date (see http://rnajournal.cshlp.org/site/misc/terms.xhtml). After 12 months, it is available under a Creative Commons License (Attribution-NonCommercial 4.0 International), as described at http://creativecommons.org/licenses/by-nc/4.0/.
Email Alerting Receive free email alerts when new articles cite this article - sign up in the box at the Service top right corner of the article or click here.

To subscribe to $R N A$ go to:

http://rnajournal.cshlp.org/subscriptions 